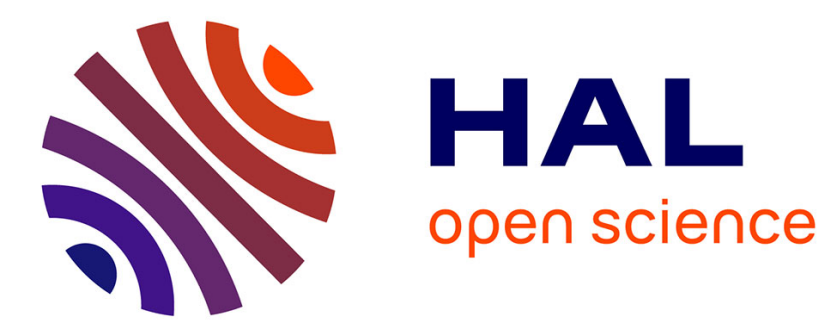

\title{
Impacts of supercapacitors on battery lifetime in hybrid energy storage system in building integrated photovoltaic DC micro-grid
}

\author{
Margot Gaetani-Liseo, Corinne Alonso, Bruno Jammes
}

\section{To cite this version:}

Margot Gaetani-Liseo, Corinne Alonso, Bruno Jammes. Impacts of supercapacitors on battery lifetime in hybrid energy storage system in building integrated photovoltaic DC micro-grid. 7th International Conference on Renewable Energy Research and Applications (ICRERA 2018), IEEE, Oct 2018, Paris, France. hal-01963535

\author{
HAL Id: hal-01963535 \\ https://hal.laas.fr/hal-01963535
}

Submitted on 8 Jan 2019

HAL is a multi-disciplinary open access archive for the deposit and dissemination of scientific research documents, whether they are published or not. The documents may come from teaching and research institutions in France or abroad, or from public or private research centers.
L'archive ouverte pluridisciplinaire HAL, est destinée au dépôt et à la diffusion de documents scientifiques de niveau recherche, publiés ou non, émanant des établissements d'enseignement et de recherche français ou étrangers, des laboratoires publics ou privés. 


\title{
Impacts of supercapacitors on battery lifetime in hybrid energy storage system in building integrated photovoltaic DC micro-grid
}

\author{
M. Gaetani-Liseo, C. Alonso and B. Jammes \\ LAAS-CNRS \\ University Paul SABATIER - TOULOUSE 3 \\ Toulouse, FRANCE \\ mgaetani@laas.fr, alonsoc@laas.fr, jammes@laas.fr
}

\begin{abstract}
This paper focuses on a study of an hybrid energy storage system constituted by lead acid batteries and supercapacitors and designed to work in a low voltage DC microgrid supplying by photovoltaic sources and dedicated to building application. We proposed a simulation methodology in order to evaluate supercapacitors performances and behaviors for long term analysis. We quantify their impacts on battery lifetime and on the levelized cost of electricity of our storage system. This analysis has been validated on the micro-grid developed in LAASCNRS in ADREAM building integrated photovoltaic. The power profiles used for our work correspond to 1 years production and consumption data from $100 \mathrm{~m}^{2}$ floor of the building. Results of comparative studies with different load profiles, SC costs and methods to estimated battery lifetime are presented and discussed.
\end{abstract}

Index Terms-LVDC-MG; hybrid ESS; Supercapacitor; Leadacid Battery; LCOE; aging model; PV building

\section{INTRODUCTION}

Ecological issues as global warming, fossil energy depletion with increasing electrical demand is nowadays a well know challenge. One of the key to reduce our ecological footprint are initiatives as Zero Emission Building (ZEB) and autonomous buildings. To tackle this issue distributed generators as decentralized Low Voltage DC Micro-Grid (LVDC-MG) with PhotoVoltaic sources (PV) integrated in Building (BiPV) is a widely used solution for urban area [1]-[3] . Nevertheless the intermittent nature of the PV production, and the time shift between consumption and production requires Energy Storage Systems (ESS) with associated strategies [4], [5].

Within this context Hybrid Energy Storage System (HESS) with batteries and SuperCapacitors (SC) association have been attracted a considerable attention in order to improve efficiency and promote sustainable electrical network. Indeed this topology, frequently proposed in electric vehicle applications as in [6] and [7], seems appropriate to improve batteries lifetime because of the complementary performances of SC and based on the assumption that the SC lifetime isn't impacted by micro cycles. Therefore, they can avoid small batteries dischargingcharging cycles by delivering (or absorbing) the power during the irradiance (or load) intermittences [8]-[10]. The aim of this paper is to analyze the impact of the SC on the battery lifetime and on the HESS life cycle cost in building application. This analyze is based on real operations thanks to data recorded every minute in ADREAM BiPV Data Base (DB) [11]. Two different load profiles: the lighting network and the electrical outlets power profiles, two different battery aging estimation method and best and worst SC costs are used in order to compared results and achieve a complete analysis and discussion.

In II we present the existing LVDC-MG developed in the LAAS-CNRS BiPV.

Afterwards, in section III we details the ESS models and the LVDC-MG simulation algorithm, developed on Matlab (․

In section IV we define the two battery aging estimation methods used and the criterion used to analyze the HESS cost.

Finally we present, compared and discussed our results for different load power profiles and SC cost in section V.

\section{THE LVDC MG}

The LVDC-MG developed in LAAS-CNRS was described in [12]. Its architecture is presented in fig 1. The HESS associates two ESS connected in parallel to the DC bus through bidirectional DC/DC converters. ESS A is SC pack and ESS B is OPzV Lead-acid (Ld) batteries pack. These two technologies have been combined because of their different and complementary characteristics: Ld batteries are known as a mature and cheap electrochemical storage technology with a high energy density, while SC support a high number of cycles and present a high power density, but it is a very expensive technology [13]. We developed a specific power management algorithm explained in [12] and derived from DC bus signaling control [14]. This control algorithm gives the priority to SC charge and discharge, in order to avoid micro-cycles in the batteries.

ESS A is made up of Maxwell Technologies SC with maximum voltage $V_{\text {ESSA }}$ of $48 \mathrm{~V}$ and a capacity $\mathrm{C}_{S C}$ equal to $165 \mathrm{~F}$ [15]. ESS B is constituted by 6 Hoppecke OPzV 6V batteries connected in series. The nominal capacity Capnom of each battery is equal to 250Ah (@C10) [16]. The maximum voltage of EES B is $42.3 \mathrm{~V}$. The characteristics of the two ESS are summarized in table I. 


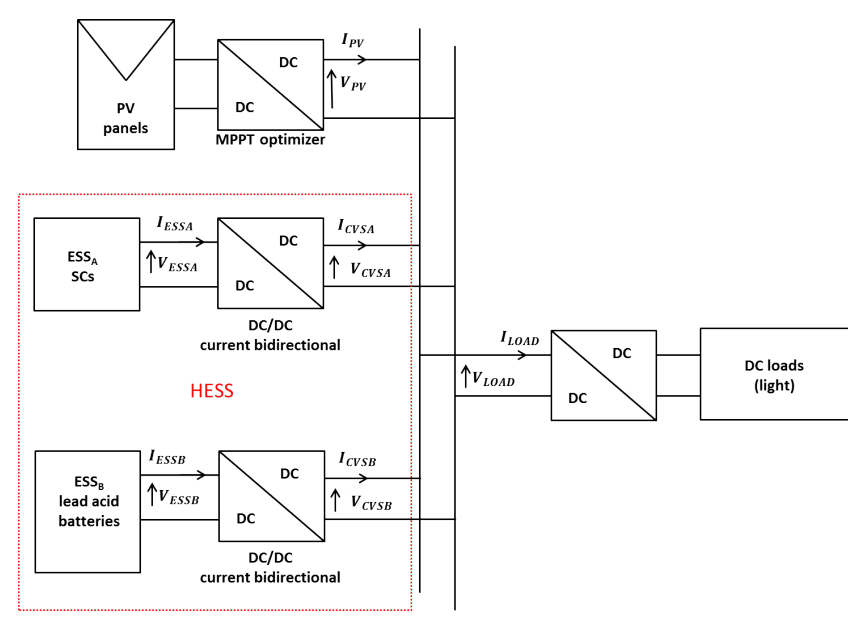

Fig. 1. Electric synoptic of the LVDC-MG developed in the LAAS-CNRS

TABLE I

MAIN CHARACTERISTICS OF ESS IN LVDC-MG

\begin{tabular}{|c|c|c|}
\hline ESSi & A : SC pack & $\begin{array}{c}\text { B : OPzV Ld } \\
\text { battery pack }\end{array}$ \\
\hline $\begin{array}{c}\text { Number of element } \\
\text { in serial connection }\left(\mathbf{n}_{\mathbf{s}}\right)\end{array}$ & 1 & 6 \\
\hline Maximum Voltage [V] & 51 & 42.3 \\
\hline Nominal Voltage [V] & 48 & 36 \\
\hline $\begin{array}{c}\text { Current range } \\
I_{E S S i}[\mathbf{A}]\end{array}$ & - & {$[-25,25]$} \\
\hline $\begin{array}{c}\text { Power ranges } \\
P_{E S S i}[\mathrm{~kW}]\end{array}$ & - & {$[-1,1]$} \\
\hline Nominal Energy [Wh] & 53 & $9000(@ \mathrm{C} 10)$ \\
\hline $\begin{array}{c}\text { State of charge range } \\
\text { (SoC) [\%] }\end{array}$ & {$[0,100]$} & {$[10,90]$} \\
\hline Investement cost $[€ / \mathbf{k W h}]$ & 24000 & 300 \\
\hline
\end{tabular}

Currents and powers have been chosen positive when EES are discharging. According to the data-sheet the maximal value of the battery current corresponds to the nominal C-rate (0.1C). To reach different values of energy installed with the technologies A or B, we connected in parallel $n_{s}$ element in each $\mathrm{ESS}_{\mathrm{i}}$. For each ESS, the investment cost proposed is an average value of installation costs given by distributors. These values are coherent to the ones publish in [17]-[19] for OPzV Ld batteries and in [20] for SC. However, SC installation cost varies a lot in the literature and few data only are available owing it is a developing technology. Usually, the cost used in papers is lower than the one we give in table I. A sensitive analysis of this parameter will be done in section $\mathrm{V}$.

\section{Simulation METhodology AND ESS MOdelS}

\section{A. PV and Load power profile data}

For our study, we selected two one year power data set from the ADREAM BiPV DB (time step $=1$ min) which are representative of the consumption associated to tertiary buildings and relevant to be supplying by LVDC MG [21]-[23]: lighting network and electrical outlets. The PV production profile corresponds to 8 panels $(2 \mathrm{kWp}$ ) of PV plant installed on the ADREAM building terrace. The lighting and electrical outlets power demand are both corresponding to $100 \mathrm{~m}^{2}$ of the second floor of the ADREAM building occupied by offices. Within this context we calculated the global capacity of the HESS in order to be autonomous.

These power profiles allowed us to determine the power profile input $\left(\mathrm{P}_{\mathrm{BAL}}\right)$ of our LVDC-MG model according to equation 1.

$$
P_{B A L}=P_{P V}-P_{L O A D_{p}}
$$

where p index can be "lighting" or "outlets" consumption power profile.

\section{B. ESS models}

1) SC model: SC are modelled by their equivalent electric Thevenin circuit (Eq. (2)), where $\mathrm{C}_{\mathrm{SC}}$ is the capacity in Farad and $\mathrm{R}_{\mathrm{SC}}$ the equivalent serial resistor given by manufacturer.

$$
\begin{array}{r}
V_{E S S A}(t)=\frac{1}{C_{S C}} * I_{E S S A}(t-1) * \Delta t \\
-R_{E S S A} * \Delta I_{E S S A}(t-1)+V_{E S S A}(t-1)
\end{array}
$$

2) Battery model: The battery model is based on the Shepherd [24] and Tremblay's [25] models, which are commonly used for PV and MG applications [26]. According to the operating range of the battery $(10 \%<\mathrm{SoC}<90 \%)$, we don't need to consider end of charge and end of discharge phenomena. In these conditions, the accuracy of a linear model is sufficient [27], [28]. Moreover, according to Tremblay's assumptions in [25], the battery temperature is considered constant, and self-discharged and Peukert effect aren't taken into account. The discrete version of the model is given by (3). $V_{O C}$ is the open circuit voltage depending on the battery SoC and determined by (4) and (5) (Ah counting), Cap nom is the nominal capacity in $A h$, and $R_{\text {ESSB }}$ is the battery internal resistance.

$$
\begin{gathered}
V_{E S S B}(t)=V_{O C}(t)-R_{E S S B} * \Delta I_{E S S B}(t-1) \\
+V_{E S S B}(t-1)
\end{gathered}
$$

The parameters $\mathrm{K}, \mathrm{E}_{0}$ and $\mathrm{R}_{\mathrm{ESSB}}$ have been identified thanks to several charging and discharging tests at constant current. Two different sets of parameters are defined for charging and discharging operations. The model has been validated with dynamic current profiles (one minute steps). In these conditions the maximum relative error is $6 \%$, which is accurate enough for our application. 


\section{Overall simulation algorithm}

The overall flow chart diagram in fig 2 represents the HESS simulation process. $\mathrm{P}_{\mathrm{ESS}}{ }^{*}$ is the power exchanged between the battery and the bus after $\mathrm{SoC}$ and $\mathrm{C}$-rate limitation.

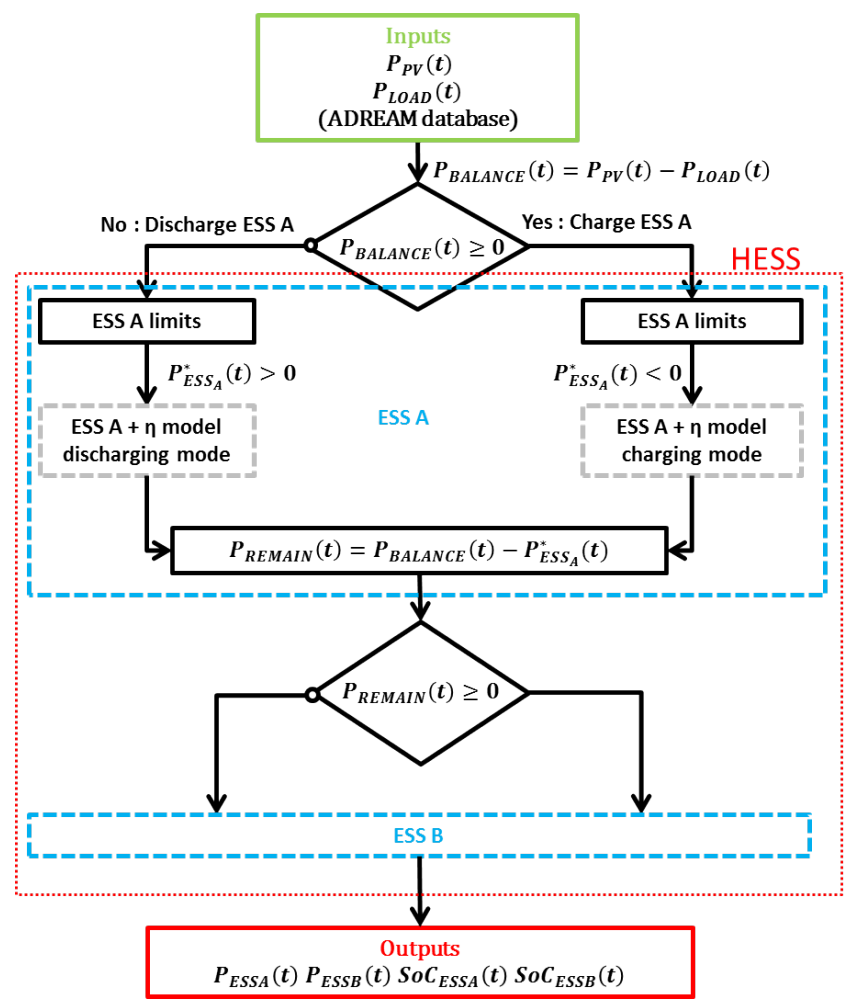

Fig. 2. Flow chart diagram of HESS simulation algorithm in LVDC-MG

The simulation process take into account the bidirectional DC/DC converter efficiency, noted $\eta(\mathrm{t})$. This efficiency which depends on the voltage and the power delivered or absorbed by $\mathrm{ESS}_{\mathrm{i}}$, where $\mathrm{i}$ is ESS A (SC) or ESS B (OPzV Ld batteries). The expression of $\eta(\mathrm{t})$ is given in 6 , where $\mathrm{f}_{\mathrm{k}}$ is a parametric quadratic function depending on $\mathrm{V}_{\mathrm{ESS}_{\mathrm{i}}}$ the $\mathrm{ESS}_{\mathrm{i}}$ voltage. Its parameters are identified thanks to experimental tests.

$$
\begin{aligned}
\eta(t)= & f_{1}\left(V_{E S S_{i}}(t)\right) * \exp ^{f_{2}\left(V_{E S S_{i}}(t)\right) *\left|P_{E S S_{i}}(t)\right|} \\
& +f_{3}\left(V_{E S S_{i}}(t)\right) * \exp ^{f_{4}\left(V_{E S S_{i}}(t)\right) *\left|P_{E S S}(t)\right|}
\end{aligned}
$$

At each time $t$ of the simulation, we solve (7), according to equations (2), (3) and (6).

$$
\left\{\begin{array}{l}
\left|P_{E S S_{i}}(t)\right|^{*} * \eta(t)-\left|P_{E S S_{i}}(t)\right|=0, \text { charging } \\
\left|P_{E S S_{i}}(t)\right| * \eta(t)-\left|P_{E S S_{i}}(t)\right|^{*}=0, \text { discharging }
\end{array}\right.
$$

Therefore, the simulation of power exchanges between the HESS and the MG takes into account the battery voltage variation, the power lost in the $\mathrm{ESS}_{\mathrm{i}}$ and in the associated DC/DC converter.

\section{CRITERION}

\section{A. Lifetime and aging battery model}

The battery life time $L_{B}$, expressed in years, can be estimated with different methods [29]. In this paper we propose to use two of them : the widely used equivalent full cycles to failure method (Ah throughput method) inspired by [30], and the Rainflow counting method [31].

1) Ah Throughput: The easy implementation of $\mathrm{Ah}$ throughput method make it the usually used in the literature to estimated batteries lifetimes. This methods proposes to compare the energy discharged $\left(\mathrm{E}_{\text {disch }}\right)$ during one year with the total energy that the battery can deliver according to its cycle lifetime at nominal deep of discharge $\left(\mathrm{DoD}_{\text {nom }}\right)$. The number of cycles to failure $\left(\mathrm{N}_{\mathrm{CF}}\right)$ at different $\mathrm{DoD}$ are given in data-sheets, and the expression of the battery lifetime in years is given by (8). In this equation, $\mathrm{E}_{\text {inst }}$ represents the battery installed energy .

$$
L_{B}=\frac{E_{\text {inst }} * D o D_{\text {nom }} * N_{C F}\left(D o D_{\text {nom }}\right)}{E_{\text {disch }}}
$$

One inconvenient of the Ah throughput method is that the lifetime estimation is based on the number of cycles to failure at fixed value of DoD. Therefore, this method doesn't take into account the nonlinearity of the $N_{C F}$ vs DoD curve, as well as the battery SoC at each cycle.

2) "Rainflow" counting: This method allows to take into account the real impact of the DoD of each cycle on the lifetime estimation [31], [32]. The DoD range is divided in $\mathrm{N}$ intervals $\operatorname{DoD}_{\mathrm{k}}(\mathrm{k}=1$ to $\mathrm{N})$. For each cycle of the battery inside the $\mathrm{DoD}_{\mathrm{k}}$ interval, the number of cycles Ncycles is incremented. At the end of the year, Ncycles $k$ values is compared with the number of cycles to failure, $N_{C F}$ at $D_{0} D_{k}$. Thus, the Cumulative Damage (CD) of the batteries is defined by (9), and the lifetime $L_{B}$ in year can be estimated by (10).

$$
\begin{gathered}
C D=\sum_{k=1}^{N} \frac{\text { Ncycles }_{k}}{N_{C F}\left(D_{o} D_{k}\right)} \\
L_{B}=\frac{1}{C D}
\end{gathered}
$$

\section{B. $L C O E$}

We propose to analyze the economical impact of the quantity of energy made by SC in the HESS according to the Levelized Cost Of Electricity (LCOE), in $€ / \mathrm{kWh}$. The LCOE is the ratio between lifecycle cost and lifecycle energy production, and allows to asses and compare electricity generators. This criteria estimates the electrical energy cost including capital expenditure, reinvestment, operational and maintenance costs (electronic interface, etc...) among the system lifetime [5], [33]-[35]. In [19], [36]-[39] the authors proposed a metric derived from the LCOE and dedicated to ESS applications. The ESS LCOE, also called Levelized Cost of Storage (LCOS), represents the cost of the electricity 
delivered by an ESS according to its lifetime estimation. The criteria can be evaluate by including different parameters as in [18], [36], where the authors propose to include in the LCOE the cost of the energy needed to charge the ESS. Moreover, in [38] the authors show that the LCOE clearly depends on the ESS applications. In our case we only focus on the ESS cost, without taking into account the PV LCOE when battery charging and the storage application is the integration of RES and to promote autonomy building.

In our study, we only consider that the batteries have to be replaced every $L_{B}$ years and the associated reinvestment cost. The LCOE of the HESS is given by (11). It is the sum of the $\mathrm{LCOE}_{\mathrm{i}}$ of each ESS, where $\operatorname{Cost}_{\mathrm{i}}(\mathrm{y})$ represents the global cost, in euros, of $\mathrm{ESS}_{\mathrm{i}}$ for the year $\mathrm{y}$, which depends on $\mathrm{L}_{\mathrm{B}}$.

$$
\begin{aligned}
& \text { LCOE }=\sum_{i=E S S_{A}}^{B} \operatorname{LCOE}_{i} \\
& L C O E_{i}=\frac{\sum_{y=0}^{H} \frac{\operatorname{Cost}_{i}(y)}{(1+r)^{y}}}{\frac{E_{d i s c h}(y)}{(1+r)^{y}}}
\end{aligned}
$$

$\mathrm{H}$ is the time horizon for the study, in years, $\mathrm{r}$ is the discount rate and $E_{\mathrm{disch}_{\mathrm{i}}}$ is the energy delivered on a year by $\mathrm{ESS}_{\mathrm{i}}$, in $\mathrm{kWh}$.

The time horizon chosen for this study is 25 years, considering that corresponds to an average value of SC calendar lifetime, according to data given in [5], [13], [20]. The discount rate can vary from $3.5 \%$ to $8 \%$ regarding the values proposed in the literature, we selected the worst value of $3.5 \%$ as proposed by [18].

\section{RESUlts AND Discussion}

In order to analyze the interest of SC in building applications, we run the HESS simulation for different values of the energy installed thanks to SC at a fixed value of the HESS energy. We propose to analyze 26 configurations of the HESS, by varying the energy stores in the SC from 0 to $2.5 \%$ of global installed energy, by step of $0.1 \%$. Fig 3 presents the power exchanged between the 3 electrical sources (DC Bus, batteries, SC), for 2 HESS configurations (without and with SC for $2.5 \%$ of the installed energy) in case of a particularly intermittent PV production day. The batteries SOC for the 2 HESS configurations are presented on this graph, in order to show the benefits of the SC on the batteries operating. This analysis is proposed for the 2 load profiles : lighting and electrical outlets.

The following subsections present the influence of the lifetime estimation method, the load profile and the SC cost on the criterion estimation, in order to validated our chosen methodology before to conclude about SC impacts.

\section{A. Influence of the battery aging model}

Figure 4 shows the battery lifetime estimation obtained for the 26 HESS configurations, for the electrical lighting network and electrical outlets power profiles. We can see that SC

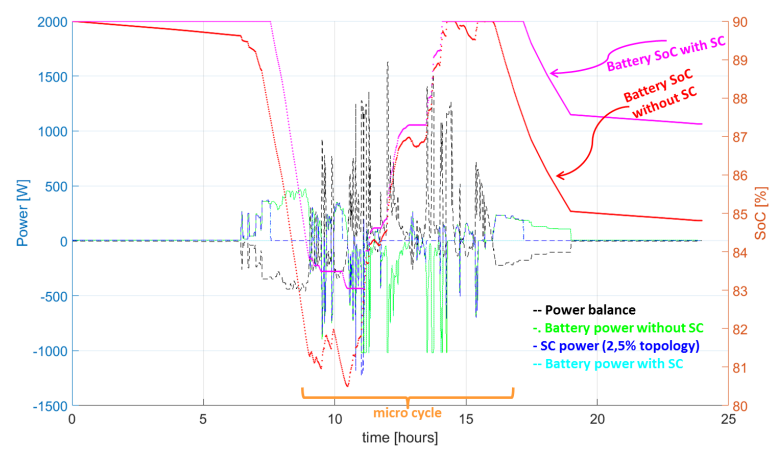

(a) lighting network load profile

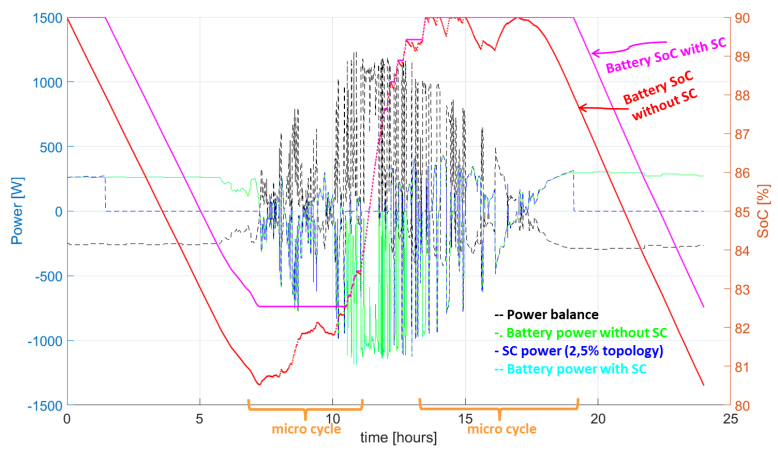

(b) electrical outlets load profile

Fig. 3. Power profiles and batteries $\mathrm{SoC}$ for lighting network and electrical outlets demands, with and without SC

improves the battery lifetime, regardless the aging method used. The batteries lifetime estimated by the Ah throughput method is higher than the one returned by the rainflow counting. Indeed, as the Ah throughput method doesn't takes into account the DoD of each cycle, it overestimates the number of cycles to failure at small DoD. For this reason, we select the rainflow counting method for the rest of the paper.

This results allow us to already say that SC impact study have to consider battery recycling. As a matter of fact, improving battery lifetime allows to increase the sustainability of our system by decreasing the replacement rate.

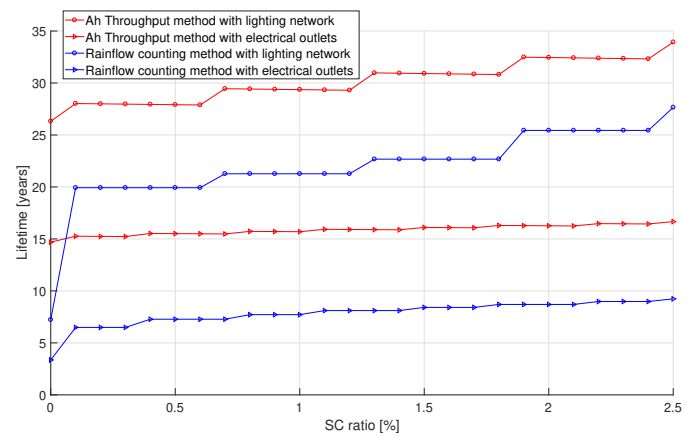

Fig. 4. Battery aging estimation calculated by "Rainflow Counting" and "Ah Throughput" method

In future works it would be interesting to improve the rainflow counting method by taking into account the $\mathrm{SoC}$ at 
each cycle, but this analyze needs more information from the manufacturers or long experiments.

\section{B. Load profile impact}

Figure 5 shows the LCOE of the HESS normalized by the LCOE of configuration with only $\mathrm{OPzV}$ battery for different load profiles.

In spite of the SC significantly increases the lifetime of the HESS when the DC bus supplies the lighting network (fig. 4), the LCOE of the HESS never decreases when we increase the percentage of the installed energy store in the SC. The price of the SC installed in our LVDC-MG is the reason of this (table I), and we will show in the next section that this trend could be reversed by using cheaper SC.

When the load of the LVDC-MG are the electrical outlets, the effect of the $\mathrm{ESS}_{\mathrm{A}}$ size is more significant. Indeed, when $0.1 \%$ of the installed energy is constituted by $\mathrm{SC}$, we note a small decrease of the LCOE. If we look at the $\mathrm{P}_{\text {bal }}$ profile, we could see more frequent change between charge and discharge compare to the lighting network, which generates more microcycles in the HESS. According to the curves presented in figure 4, the SC seems mainly useful in the case of the outlets load power profile.

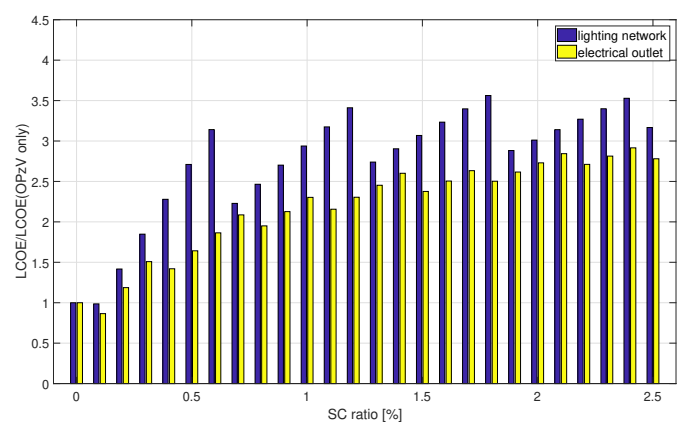

Fig. 5. The LCOE of the HESS normalized by the LCOE of OPzV battery, for the both load power profiles

\section{SC cost}

With the cost of the SC chosen for our analysis, we can obtain a small decrease of the LCOE when considering the electrical outlets power profile, but in the literature the SC cost varies from 255 to $30000 € / \mathrm{kWh}$ [13], [19], [20]. The figure 6 presents the battery lifetime and the HESS LCOE normalized for three different SC costs : the lowest values (255 €/kWh), the average values of the value found in the literature (17200 €/kWh) and the cost of the SC installed in our LVDC-MG (24000 €/kWh).

We can see that for a price of $255 € / \mathrm{kWh}$ the SC reduce the HESS LCOE. Anyway, adding a small amount of SC to the HESS reduces the global LCOE in case of electrical outlets load profiles. Furthermore, if we consider the ecologic replacement cost of the battery and the development of SC in the future, the proposed HESS could become even more attractive.

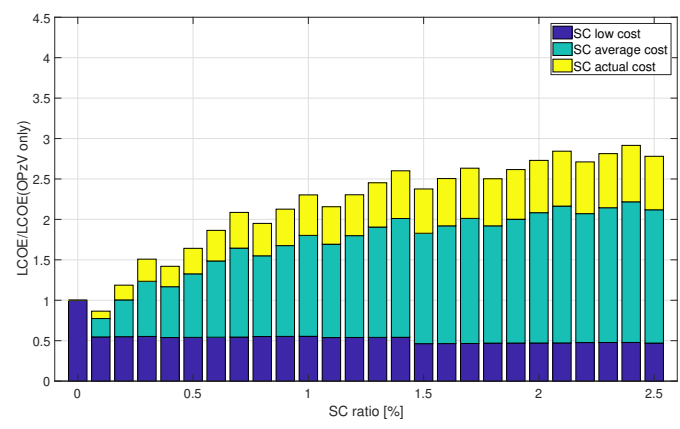

Fig. 6. LCOE for different SC costs in case of the electrical outlets power profile

\section{CONCLUSION}

In this paper we proposed a model of LVDC-MG to analyze the impacts of SC combined with $\mathrm{OPzV} \mathrm{Ld}$ batteries in an HESS. The target application of this work is electrical autonomous BiPV. This model was simulated for different types of LVDC-MG load (lighting and electrical outlets). The power load profiles extracted from ADREAM BiPV DB allow to analyze the impact of SC on batteries lifetime in real operating conditions. This analysis shows the $\mathrm{SC}$ have a positive impact on battery lifetime, by avoiding micro-cycles to the batteries. Before to conclude on the benefit of the SC, we analyzed how the battery aging estimation method and the cost of the SC influence the HESS global LCOE. At the end of this study, and according to the model used to simulated our LVDC-MG, we can conclude that adding a small amount of SC to Ld battery could reduces the LCOE of the storage system for some power load profiles. Furthermore, if we consider the ecologic replacement cost of the battery, the supposed that HESS with SC dedicated to stationary storage for autonomous BiPV application becomes even more attractive.

\section{REFERENCES}

[1] Y. Mizuno, T. Baba, Y. Tanaka, F. Kurokawa, M. Tanaka, I. Colak, and N. Matsui, "Estimation of optimum capacity of battery by combined use of a renewable energy system and distributed emergency generators in a large hospital," in 2017 IEEE 6th International Conference on Renewable Energy Research and Applications, (San Diego, CA, USA), IEEE, Nov. 2017.

[2] T. Atasoy, H. E. Akn, and . Erin, "An analysis on smart grid applications and grid integration of renewable energy systems in smart cities," in Renewable Energy Research and Applications (ICRERA), 2015 International Conference on, pp. 547-550, IEEE, 2015.

[3] S. S. Kola, "A Review on Optimal Allocation and Sizing Techniques for DG in Distribution Systems," International Journal of Renewable Energy Research (IJRER), vol. 8, pp. 1236-1256, Sept. 2018.

[4] C. Natesan, S. K. Ajithan, S. Chozhavendhan, and A. Devendiran, "Power Management Strategies In Microgrid: A Survey," International Journal Of Renewable Energy Research, vol. 5, no. 2, pp. 334-340, 2015.

[5] M. Aneke and M. Wang, "Energy storage technologies and real life applications A state of the art review," Applied Energy, vol. 179, pp. 350-377, Oct. 2016.

[6] J. Shen, S. Dusmez, and A. Khaligh, "Optimization of Sizing and Battery Cycle Life in Battery/Ultracapacitor Hybrid Energy Storage Systems for Electric Vehicle Applications," IEEE Transactions on Industrial Informatics, vol. 10, pp. 2112-2121, Nov. 2014 
[7] D. Haifeng and C. Xueyu, "A Study on Lead Acid Battery and Ultracapacitor Hybrid Energy Storage System for Hybrid City Bus," in 2010 International Conference on Optoelectronics and Image Processing, (Haiko, Hainan, China), pp. 154-159, IEEE, Nov. 2010.

[8] D. B. W. Abeywardana, B. Hredzak, and V. G. Agelidis, "Batterysupercapacitor hybrid energy storage system with reduced low frequency input current ripple," in Renewable Energy Research and Applications (ICRERA), 2015 International Conference on, pp. 328-332, IEEE, 2015.

[9] A. Di Napoli, D. Missori, and C. Polini, "Combined storage system for energy saving," in Power Electronics Electrical Drives Automation and Motion (SPEEDAM), 2010 International Symposium on, pp. 92-97, IEEE, 2010

[10] R. A. Dougal, S. Liu, and R. E. White, "Power and life extension of battery-ultracapacitor hybrids," IEEE Transactions on components and packaging technologies, vol. 25, no. 1, pp. 120-131, 2002.

[11] "ADREAM project website https://www.laas.fr/public/fr/le-projetadream (2017-01-10), author = LAAS-CNRS."

[12] J. Dulout, C. Alonso, L. Sguier, and B. Jammes, "Development of a photovoltaic low voltage DC microgrid for buildings with energy storage systems," in ELECTRIMACS 2017, vol. 2017, p. 6p, 2017.

[13] P. Nikolaidis and A. Poullikkas, "Cost metrics of electrical energy storage technologies in potential power system operations," Sustainable Energy Technologies and Assessments, vol. 25, pp. 43-59, Feb. 2018.

[14] Kai Sun, Li Zhang, Yan Xing, and J. M. Guerrero, "A Distributed Control Strategy Based on DC Bus Signaling for Modular Photovoltaic Generation Systems With Battery Energy Storage," IEEE Transactions on Power Electronics, vol. 26, pp. 3032-3045, Oct. 2011.

[15] "Maxwell technologies Enablig Energy's Future."

[16] "Hoppecke power from innovation."

[17] H. Zsiborcs, N. Hegedsn Baranyai, A. Vincze, I. Hber, and G. Pintr "Economic and Technical Aspects of Flexible Storage Photovoltaic Systems in Europe," Energies, vol. 11, p. 1445, June 2018.

[18] V. Jlch, T. Telsnig, M. Schulz, N. Hartmann, J. Thomsen, L. Eltrop, and T. Schlegl, "A Holistic Comparative Analysis of Different Storage Systems using Levelized Cost of Storage and Life Cycle Indicators," Energy Procedia, vol. 73, pp. 18-28, June 2015.

[19] B. Zakeri and S. Syri, "Electrical energy storage systems: A comparative life cycle cost analysis," Renewable and Sustainable Energy Reviews, vol. 42, pp. 569-596, Feb. 2015.

[20] A. Wanitschke, N. Norman, and F. Schaller, "Economic and environmental cost of self-sufficiency - analysis of an urban micro grid," Energy Procedia, vol. 135, pp. 445-451, 2017.

[21] A. Dolara, M. Longo, and M. Roscia, "Case study of light energy saving," in Renewable Energy Research and Applications (ICRERA), 2014 International Conference on, pp. 127-132, IEEE, Oct. 2014.

[22] A. Thakur, L. Kumar, H. K. Romana, and R. K. Malik, "Energy Consumption Attributes in Residential Buildings- A Case Study of Replacing Conventional Electrical Appliances with Energy Efficient Appliances," International Journal of Renewable Energy Research (IJRER), vol. 7, pp. 1950-1955, Dec. 2017.

[23] B. Zhong, X. Li, and Z. Zou, "Evaluating method of effectiveness of light energy's utilization based on service requirement," in Renewable Energy Research and Applications (ICRERA), 2015 International Conference on, pp. 246-251, IEEE, 2015.

[24] C. M. Shepherd, "Design of primary and secondary cells," Journal of electrochemical society, pp. 657-664, July 1965.

[25] O. Tremblay, L.-A. Dessaint, and A.-I. Dekkiche, "A generic battery model for the dynamic simulation of hybrid electric vehicles," in Vehicle Power and Propulsion Conference, 2007. VPPC 2007. IEEE, pp. 284 289, Ieee, 2007.

[26] V. Prasad and B. P. Divakar, "Real Time Estimation of SOC and $\mathrm{SOH}$ of Batteries," International Journal of Renewable Energy Research (IJRER), vol. 8, pp. 44-55, Mar. 2018

[27] O. Tremblay and L.-A. Dessaint, "Experimental validation of a battery dynamic model for EV applications," World Electric Vehicle Journal, vol. 3, no. 1, pp. 1-10, 2009.

[28] Y. Zhang, S. Lyden, B. L. de la Barra, and M. E. Haque, "Optimization of Tremblay's battery model parameters for plug-in hybrid electric vehicle applications," in Universities Power Engineering Conference (AUPEC), 2017 Australasian, pp. 1-6, IEEE, 2017.

[29] R. Dufo-Lpez, J. M. Lujano-Rojas, and J. L. Bernal-Agustn, "Comparison of different leadacid battery lifetime prediction models for use in simulation of stand-alone photovoltaic systems," Applied Energy, vol. 115, pp. 242-253, Feb. 2014.
[30] H. Bindner, T. Cronin, and P. Lundsager, "Lifetime modelling of lead acid batteries.," Riso R 1515, Riso National laboratory, Roskilde (DK). Wind Energy Department, 2005. OCLC: 826678302.

[31] S. D. Downing and D. F. Socie, "Simple rainflow counting algorithms," International journal of fatigue, vol. 4, no. 1, pp. 31-40, 1982.

[32] R. Kanapady, K. Y. Kyle, and J. Lee, "Battery life estimation model and analysis for electronic buses with auxiliary energy storage systems," in Applied Power Electronics Conference and Exposition (APEC), 2017 IEEE, pp. 945-950, IEEE, 2017.

[33] F. Ueckerdt, L. Hirth, G. Luderer, and O. Edenhofer, "System LCOE: What are the costs of variable renewables?," Energy, vol. 63, pp. 61-75, Dec. 2013.

[34] G. Di Francia, "The impact of recycling policies on PV LCOE," in ICRERA, (Madrid Spain), pp. 979-983, IEEE, Oct. 2013.

[35] D. Kumar, "Cost minimization strategy for sattellite solar power station," International Journal Of Renewable Energy Research, vol. 8, Mar. 2018.

[36] C. S. Lai and M. D. McCulloch, "Levelized cost of electricity for solar photovoltaic and electrical energy storage," Applied Energy, vol. 190, pp. 191-203, Mar. 2017.

[37] V. Jlch, "Comparison of electricity storage options using levelized cost of storage (LCOS) method," Applied Energy, vol. 183, pp. 1594-1606, Dec. 2016.

[38] B. Battke, T. S. Schmidt, D. Grosspietsch, and V. H. Hoffmann, "A review and probabilistic model of lifecycle costs of stationary batteries in multiple applications," Renewable and Sustainable Energy Reviews, vol. 25, pp. 240-250, Sept. 2013.

[39] I. Pawel, "The Cost of Storage How to Calculate the Levelized Cost of Stored Energy (LCOE) and Applications to Renewable Energy Generation," Energy Procedia, vol. 46, pp. 68-77, 2014. 